\title{
THE NATURAL APPROACH OF TRIGONOMETRIC INEQUALITIES - PADÉ APPROXIMANT
}

\section{GABRIEL BERCU}

Abstract. The aim of this work is to provide simple proofs of some remarkable trigonometric inequalities: Jordan inequality, Kober inequality, Becker-Stark inequality, Wu-Srivastava inequality. The proofs are based on Padé approximant method. We also obtain rational refinements for these inequalities.

Mathematics subject classification (2010): 41A21, 26D05, 26D15, 33B10.

Keywords and phrases: Trigonometric inequalities, Padé approximant, rational refinement.

\section{REFERENCES}

[1] U. ABEL, D. CACCIA, A sharpening of Jordan's inequality, Amer. Math. Mon., 93 (7) (1986) 568 569.

[2] M. Becker, E. L. StAR K, On a hierarchy of quolynomial inequalities for $\tan x$, Univ. Beograd. Publ. Elektrotehn. Fak. Ser. Mat. Fiz. (602-633) (1978) 133-138.

[3] P. S. Bullen, A Dictionary of Inequalities, Vol. 97 of Pitmann Monographs and Surveys in Pure and Applied Mathematics, Longman, Harlow, UK, (1998).

[4] L. Debnath, C. Mortici, L. Zhu, Refinements of Jordan-Steckin and Becker-Stark inequalities, Results Math. 67, (1-2), (2015) 207-215.

[5] W.-D. JIANG, Q.-M. LUO, F. QI, Refinements and sharpening of some Huygens and Wilker Type inequalities, Turk. J. Anal. Number Theory, 2 (4) (2014) 134-139.

[6] R. KlÉn, M. Visuri, M. VuORInen, On Jordan type inequalities for hyperbolic functions, J. Inequal. Appl. 2010 (2010), Article ID 362548, 14 pages.

[7] H. Kober, Approximation by integral functions in the complex domain, Trans. Am. Math. Soc. 56 (1994), 7-31.

[8] D. S. Mitrinović, Analytic Inequalities, Springer-Verlag, Berlin, (1970).

[9] C. MoRTICI, The natural approach of Wilker-Cusa-Huygens Inequalities, Math. Inequal. Appl. 14 (3) (2011) 535-541.

[10] C. MorTiCI, A subtly analysis of Wilker inequality, Appl. Math. Comput. 231 (2014) 516-520.

[11] C. Mortici, H.-M. SRIVASTAVA, Estimates for the arctangent function related to Shafer's inequality, Colloq. Math. 136 (2) (2014) 263-270.

[12] F. QI, D.-W. NIU, B. N. GuO, Refinements, generalizations, and applications of Jordan's inequality and related problems, J. Inequal. Appl. 2009 (2009), Article ID 271923, 52 pages.

[13] J. SÁNDOR, On new refinements of Kober's and Jordan's trigonometric inequalities, Notes Number Theory Discrete Math. 19 (1) (2013) 73-83.

[14] Z. J. Sun, L. ZHu, Simple proofs of the Cusa-Huygens-Type and Becker-Stark-Type inequalities, J. Math. Inequal. 7 (4) (2013) 563-567.

[15] S.-H. WU, H. M. SRIVASTAVA, A weighted and exponential generalization of Wilker's inequality and its applications, Integr. Transf. Spec. Funct. 18 (7-8) (2007) 529-535.

[16] L. ZHU, J. HuA, Sharpening the Becker-Stark inequalities, J. Inequal. Appl. 2010 (2010), Article ID 931275, 4 pages. 